\title{
Review Article \\ MicroRNAs: Novel Players in Cancer Diagnosis and Therapies
}

\author{
Aaron L. Oom, ${ }^{1}$ Brock A. Humphries, ${ }^{1,2}$ and Chengfeng Yang ${ }^{1,2,3}$ \\ ${ }^{1}$ Department of Physiology, Michigan State University, East Lansing, MI 48824, USA \\ ${ }^{2}$ Cellular and Molecular Biology Graduate Program, Michigan State University, East Lansing, MI 48824, USA \\ ${ }^{3}$ Center for Integrative Toxicology, Michigan State University, East Lansing, MI 48824, USA \\ Correspondence should be addressed to Chengfeng Yang; yangcf@msu.edu
}

Received 10 June 2014; Accepted 16 June 2014; Published 2 July 2014

Academic Editor: Yiguo Jiang

Copyright (C) 2014 Aaron L. Oom et al. This is an open access article distributed under the Creative Commons Attribution License, which permits unrestricted use, distribution, and reproduction in any medium, provided the original work is properly cited.

\begin{abstract}
First discovered in 1993, microRNAs (miRNAs) have been one of the hottest research areas over the past two decades. Oftentimes, miRNAs levels are found to be dysregulated in cancer patients. The potential use of miRNAs in cancer therapies is an emerging and promising field, with research finding miRNAs to play a role in cancer initiation, tumor growth, and metastasis. Therefore, miRNAs could become an integral part from cancer diagnosis to treatment in future. This review aims to examine current novel research work on the potential roles of miRNAs in cancer therapies, while also discussing several current challenges and needed future research.
\end{abstract}

\section{Introduction}

MicroRNAs (miRNAs) were first discovered by Lee et al. in 1993 [1]. In the first decade after their discovery a particular focus was placed on their importance in development as first illustrated by Ambros' group. This developmental focus segued perfectly into cancer applications and has been, for the past decade, the drive for much of the research in miRNA potential use for cancer therapy.

miRNAs are small noncoding RNAs that are produced naturally by the cell. They function by sequence-specific binding of a seed sequence to the $3^{\prime}$ end of the untranslated region (UTR) of a target mRNA, causing the mRNA to then be degraded or to be translationally inhibited [2]. miRNAs have been thought to regulate two-thirds of the entire protein coding genome [3]. The expression of miRNAs themselves can also be regulated similarly to that of protein coding genes. Whether through genetic or epigenetic shifts, the expression levels of miRNAs are often altered in many cancers, resulting in abnormal increases or decreases [4]. These alterations have been shown to play a part in almost all facets of cancer development and progression.

Recent research has shown that tumor suppressors, such as phosphatase and tensin homolog (PTEN) [5-10] and p53 [11], can be potential targets of miRNAs. Typically downregulated in many cancers, the loss of these critical tumor suppressors can greatly increase cell proliferation and tumor progression. Furthermore, the link between some tumor suppressors and survival genes, such as the link between PTEN and the survival effector, AKT (also known as protein kinase $B$ or $\mathrm{PKB}$ ), may indicate therapeutic means of targeting metastasis, tumor growth, and cancer survival. And indeed, current research is examining these miRNAs that target tumor suppressors both on their own and in combination with traditional therapies, such as cisplatin [9, 10], etoposide, and ionizing radiation [11].

Additionally, certain families of miRNAs have been implicated in epithelial-to-mesenchymal transition (EMT), a critical component of cancer metastasis. EMT is typically marked by changes in morphology and cytoskeletal rearrangement. For example, one emerging family in cancer metastasis is the miR-200 family which is known for directly targeting the Ecadherin suppressors zinc finger E-box binding homeobox 1 and homeobox 2 (ZEB1 and ZEB2) [12, 13]. The loss of miR200 family members leads to decreased E-cadherin levels. This loss of E-cadherin, an integral cell to cell adhesion protein, correlates with a dramatic increase in cells going through EMT [12, 13].

This review will examine the role that miRNAs could play in cancer therapeutics. To this end, current novel research 
work on the cancer therapeutic values of miRNAs will be examined.

\section{2. miRNAs as Potential Markers for Cancer Diagnosis}

While some of the current miRNA research work focuses on targeting novel miRNA changes and investigating the mechanism involved, other research is aimed at characterizing the miRNA expression levels for particular cancer types. It is becoming apparent that the severity and stage of cancer can be associated with miRNA levels, as seen below. This is critical, as choosing the most effective treatment option is highly dependent on precisely knowing disease aggressiveness. For example, low grade cancers do not have to be treated as aggressively as high grade cancers.

This strong drive to use miRNA screening for diagnosis serves two particular purposes: as an earlier diagnosis tool and as a more efficient means of diagnosis. Circulating miRNAs have been shown to be one of the very promising biomarkers for cancer earlier diagnosis [14]. It is believed that intracellular miRNAs are packaged into exosomes or microvesicles, which are then expelled from cells and enter the blood stream. Moreover, it has been found that circulating miRNAs are highly stable, which makes them ideal candidates serving as earlier diagnostic biomarkers for cancer [15].

For example, colorectal cancer diagnosis currently utilizes either invasive methods, such as a colonoscopy, or far less precise methods, such as fecal analysis. The often seen reluctance to comply with such measures ultimately results in much later diagnosis in patients [16]. Examining tissue and blood samples from patients of varying stages of colorectal cancer, Yong et al. showed seven miRNAs altered in both, with three of those having strong positive correlations between blood and tissue samples: miR-193a-3p, miR-23a, and miR338-5p. Interestingly, the levels of each increased as the stage of the cancer progressed, suggesting an important role mechanistically as well as diagnostically for this trio [16].

Much like colorectal cancer, prostate cancer has long suffered from ambiguities and difficulties within diagnosis methodology. The most employed diagnosis method for prostate cancer is the Gleason scale. Tumors are differentiated based on size and histological features. There is a certain gray area when it comes to this method, making it far more difficult to choose a proper course of treatment. The use of miRNAs to categorize prostate cancer subtypes could overhaul the Gleason system and present a more accurate and reliable system. To address this, Wach et al. screened two cohorts of prostate cancer patients. They found that four particular miRNAs-miR-143, miR-145, miR-200c, and miR-375-were the most dramatically altered miRNAs in the two cohorts. Of the four, miR-143, miR-145, and miR375 were best at distinguishing between malignant and nonmalignant tumors. Considering the three in conjunction, they were able to correctly distinguish between malignant and nonmalignant samples $77.6 \%$ of the time [17].

If a cancer type already has a standard method of subtype characterization it is possible for researchers to develop a miRNA screen around the molecular markers used for diagnosis; this was employed by Leivonen et al. with HER2 positive breast cancer lines and two patient cohorts. The group found a wide variety of miRNAs that downregulated HER2 and found a strong correlation between higher miR$342-5 p$ levels and survival time [18]. While this type of characterization allows for a miRNA signature to be created for various cancer subtypes and thereby offering therapeutic options, it also serves the very practical purpose of diagnosis.

Of the possible benefits that can be derived from miRNA screens, the most substantial is the uniformity. We are currently able to detect miRNA levels from a basic serum sample. The power of taking a single blood sample from a patient and being able to address a wide variety of cancers from one miRNA screen is staggering.

\section{3. miRNAs as Potential Cancer Therapies}

Diagnosing from miRNA screens is not the only possible application; there is emerging evidence that it is possible to manipulate miRNA levels to enhance current cancer therapeutics. The miRNA screening process has allowed for the rise of more specialized research that focuses on these significantly dysregulated miRNAs and what they may be targeting. Reintroduction or inhibition of the dysregulated miRNA in conjunction with traditional cancer therapies could make for a more efficient treatment plan. This natural progression of methodology has yielded numerous miRNAs in each cancer type that can also serve as potential targets on their own in various cancers. Many miRNAs have been shown to have therapeutic potentials; in the following sections only a few selected miRNAs and target pathways are discussed to help highlight important and significant areas of the research.

3.1. miRNAs Targeting Receptor Tyrosine Kinases. Receptor tyrosine kinases (RTKs) are well known for their role in upregulating angiogenesis and cell proliferation in many cancers and have therefore served as critical drug targets in cancer treatment [19]. Fasanaro et al. found that miR210 expression is significantly upregulated under hypoxic conditions. Hypoxic conditions are typical in several cancer microenvironments, such as tumor cores and bone cancers. MicroRNA-210 expression triggered the formation of capillary structures and directly targeted ephrin $3 \mathrm{~A}$, a ligand for a member of the RTK subfamily, ephrin receptors [20].

Comparable findings have also been found across various cancers, such as non-small cell lung cancers, breast cancer, and glioblastomas. Oneyama et al. showed that miR-99a expression significantly inhibited tumor growth and cell proliferation in lung cancers. The group showed that miR-99a was targeted by oncogenic proteins such as Ras and epidermal growth factor (EGF). Furthermore, they showed that miR99a targets the RTK, fibroblast growth factor 3 (FGFR3) [21]. Similarly, Acunzo et al. found that miR-27a targets MET, a well-known oncogene, and epidermal growth factor receptor (EGFR) in non-small cell lung cancers [22]. Mackiewicz et al. found that miR-34a significantly reduces cell migration in breast cancer cell lines by directly targeting the RTK, AXL [23]. Likewise, Feng et al. showed that lin28 expression significantly upregulates HER2 in breast cancer and correlates 
with a poorer prognosis in patients when highly expressed. Furthermore, lin28 expression-which is known to target let$7 \mathrm{a}$-significantly increases cell growth in vitro [24]. Finally, Rao et al. showed that upregulation of miR-219-5p inhibited cell growth and cell migration in glioblastoma cells via EGFR targeting [25]. Together these findings suggest an alternative method of targeting RTKs across a variety of cancers.

3.2. miRNAs Targeting Bcl-2 Family Members. Bcl-2 family members are either antiapoptotic or proapoptotic, with dysregulation often occurring in both types in many cancers. Kwon et al. found that miR-193a-3p directly targets the antiapoptotic Mcl-1 with stable expression of this miR inhibiting cell growth, inducing apoptosis, and creating DNA damage in the glioblastoma cell line, U-251 [26]. Zhang et al. showed that overexpression of miR-29a significantly inhibited cell proliferation and promoted apoptosis in U2OS and SAOS-2 osteosarcoma cells. This group also showed in a luciferase reporter assay that miR-29a directly inhibits Bcl-2 and Mcl-1, both antiapoptotic family members [27]. Likewise, Ji et al. found that low miR-133a levels corresponded to a poorer prognosis in osteosarcoma patients. When miR-133a was expressed in vivo, the group found that tumor volumes were significantly suppressed. MicroRNA-133a was found to target $\mathrm{Bcl}-\mathrm{xL}$ and $\mathrm{Mcl}-1$ and promoted apoptosis upon overexpression [28]. Similarly in pancreatic cancer Guo et al. showed that restoration of miR-491-5p yielded a slight increase in cell death and a slight decrease in cell proliferation by targeting Bcl-xL and TP53 in SW1990 pancreatic cancer cells [29]. Ji et al. showed that a restoration of miR-34 as well inhibited cell proliferation in vitro and tumor growth in vivo in MiaPaCa2 pancreatic cancer cells through direct $\mathrm{Bcl}-2$ targeting [30].

Targeting of Bcl-2 was also found in colorectal cancer and leukemia by Zhang and Cimmino. Zhang et al. found that miR-148a significantly induced cell apoptosis by directly targeting $\mathrm{Bcl}-2$ in $\mathrm{RKO}$ and Levo colorectal cancer cell lines [31], while Cimmino et al. showed that when miR-15 and miR-16 were reexpressed cell apoptosis was significantly upregulated in MEG-01 leukemia cells by directly targeting Bcl-2 [32]. Lastly, Lin et al. found that upregulation of miR-122 decreased relative cell numbers and significantly increased caspase- 3 activity by directly targeting Bcl-w, an antiapoptotic family member, in hepatocellular carcinoma cell lines [33]. With many Bcl-2 family inhibitors still locked in clinical trials, miRNAs that target the family could prove to be another source of Bcl-2 inhibitors.

3.3. miRNAs Targeting the Ras Subfamily. One of the best known oncogene families is the Ras subfamily. The Ras subfamily is critically involved in cell survival, angiogenesis, and proliferation. Upregulation of Ras is found in numerous cancers and causes unchecked growth and invasiveness [34]. Thus, it serves as a valuable target in cancer treatments.

Kasinski and Slack showed that miR-34 inhibits cell proliferation and migration in vitro in lung cancer cells by targeting K-Ras in addition to other oncogenes. Additionally, ectopic expression of miR-34 significantly suppressed tumor growth in vivo [35]. Similarly, Sun et al. found that downregulation of miR-31 significantly decreased cell proliferation in vitro and showed a significant decrease in tumor size in vivo with Caco-2 and HT-29 human colorectal adenocarcinoma cells by directly targeting RAS p21 GTPase activating protein 1 (RASA1), a regulator of the RAS-MAPK pathway [36].

Shin et al. found that expression of miR-181a significantly suppressed cell proliferation and colony formation in squamous cell carcinoma cells. This group also found that miR181a directly targets K-Ras in squamous cell carcinoma cells [37]. More specifically, Jang et al. showed that restoration of miR-636 by suppression of adenine nucleotide translocase 2 (ANT2) significantly reduces cell proliferation in vitro and tumor growth in vivo by directly targeting Ras in hepatocellular carcinoma cells [38].

Finally, Wang et al. showed that restoration of miR-451 significantly inhibits cell proliferation and colony formation and induces apoptosis in human non-small cell lung cancer cells. Additionally, expression of miR-451 in vivo significantly reduced tumor growth. They showed that miR-451 directly targets Ras-related protein 14 (RAB14) in human non-small cell lung cancer cells [39].

Additional miRNAs having potential therapeutic values are listed in Table 1.

\section{4. miRNAs as Cancer Therapy Resistance Mediators}

A large amount of research has also focused on the use of miRNAs in conjunction with traditional therapies and their ability to mediate therapeutic responses. For the purpose of discussion, miRNAs that confer resistance to therapy when highly expressed will be considered resistance mediators. In the interest of space, only a few selected miRNAs are discussed in the following sections.

4.1. $m i R-21$. One prominent example of a resistance mediator is miR-21. Current research suggests that one role of miR-21 in cancer is regulating DNA repair and maintenance in response to treatment, particularly nucleoside analogs. Paik and colleagues found that using a miR-21 inhibitor significantly reduced resistance to gemcitabine in Panc-1, a human pancreatic cancer cell line [78]. Likewise, Hwang and colleagues showed that inhibition of miR-21 dramatically decreased cell growth in PL45 cells, a pancreatic ductal adenocarcinoma cell line, when treated with fluorouracil (5-FU) [79]. Both 5-FU and gemcitabine are chemotherapy agents that act as nucleoside analogs, raising the possibility of a role of miR-21 in DNA repair.

To strengthen this, Wong et al. found that prolonged exposure to temozolomide, an alkylating agent, significantly upregulated miR-21 expression in D54MG glioblastoma cells. Inhibition of miR-21 drastically increased cell death when resistant D54MG cells were treated with temozolomide [81]. Additionally, Griveau et al. showed that when miR-21 was inhibited with a locked nucleic acid in U87MG glioblastoma cells, the cells were far more susceptible to radiationinduced cell death [82]. Deng et al. found that miR-21 also regulates thymidine phosphorylase, dihydropyrimidine 
TABLE 1: miRNAs explored as potential cancer therapeutic agents.

\begin{tabular}{|c|c|c|}
\hline $\mathrm{miR}$ & Cancer type & Targets \\
\hline let-7a & Breast [24], endometrial [40] & HER2 and aurora-B \\
\hline miR-15 and miR-16 & Leukemia [32] & $\mathrm{Bcl}-2$ \\
\hline $\operatorname{miR}-21$ & Glioblastoma, breast [41] & E-cadherin-ZEB1/2 pathway \\
\hline $\mathrm{miR}-21$ and $\mathrm{miR}-181 \mathrm{~b}$ & Glioma [42] & FOS \\
\hline miR-22 and miR-200b & Gastric [43] & Wnt-1 pathway \\
\hline miR-26a & Liver, prostate, skin [44], bladder [45] & Lin28B, Zcchcl1, and HMGA1 \\
\hline miR-27a & Lung [22], breast [46] & MET, EGFR, and PI3K-AKT pathway \\
\hline $\mathrm{miR}-27 \mathrm{~b}$ & Colorectal $[47]$ & VEGFC \\
\hline miR-29a & Osteosarcoma [27] & Bcl-2, Mcl-1 \\
\hline miR-31 & Colorectal [36] & RASA1 \\
\hline miR-34 & $\begin{array}{l}\text { Breast (34a) [23], pancreatic [30], lung [35], lung (34a, c) } \\
{[48]}\end{array}$ & AXL, Bcl-2, K-Ras, and PDGFR- $\alpha / \beta$ \\
\hline $\operatorname{miR}-99 a$ & Lung $[21]$ & mTOR/FGFR3 \\
\hline miR-106b-5p & Glioma [49] & RBL1, RBL2, and CASP8 \\
\hline miR-122 & Liver [33] & Bcl-w \\
\hline miR-130b & Pancreatic $[50]$ & STAT3 \\
\hline miR-133a & Osteosarcoma [28] & Bcl-xL and Mcl-1 \\
\hline miR-138 & Glioblastoma [51] & EZH2-CDK4/6-pRb-E2F1 pathway \\
\hline miR-145 & Ovarian [52] & p70S6K1 and MUC1 \\
\hline miR-148a & Colorectal [31], liver [53] & Bcl-2 and Met/Snail pathway \\
\hline miR-150 & Lung [54] & $\mathrm{p} 53$ \\
\hline miR-155 & Breast $[46,55,56]$ & VHL, TP53INP1, and PI3K-AKT pathway \\
\hline miR-181 & Squamous cell (181a) [37], breast [57] & $\begin{array}{l}\text { K-Ras and ataxia telangiectasia mutated } \\
(\text { ATM })\end{array}$ \\
\hline miR-185 and miR-342 & Prostate $[58]$ & SREBP pathway \\
\hline miR-193a-3p & Glioblastoma [26] & Mcl-1 \\
\hline miR-205 & Oral [59] & Axin 2 \\
\hline miR-210 & Hypoxic conditions [20] & Ephrin-A3 \\
\hline miR-219-5p & Glioblastoma [25] & EGFR \\
\hline miR-221 & Pancreatic [60], breast $[61]$ & PTEN, p27kip1, p57kip2, and PUMA \\
\hline miR-301a & Breast [62] & PTEN \\
\hline miR-449a and $-449 b$ & Retinoblastoma [63] & E2F transcription factors \\
\hline $\operatorname{miR}-451$ & Lung [39] & RAB14 \\
\hline $\operatorname{miR}-491-5 p$ & Pancreatic [29] & TP53 and Bcl-xL \\
\hline $\operatorname{miR}-494$ & Glioma [64] & p190B RhoGAP \\
\hline $\operatorname{miR}-497$ & Neuroblastoma [65] & WEE1 \\
\hline miR-636 & Liver [38] & Ras \\
\hline miR-708 & Bladder [66] & Caspase-2 \\
\hline
\end{tabular}

dehydrogenase, and human DNA mismatch repair protein Msh2 (hMSH2) - proteins involved in DNA repair and synthesis-in the colon cancer cell line HT-29. When miR-21 was downregulated the cells were significantly resensitized to 5FU treatment and irradiation [85]. Lastly, Valeri et al. showed that miR-21 was directly targeting hMSH2 and creating 5-FU resistance [86]. All together, these findings strongly suggest that miR-21 is playing an important role in cancer cell DNA repair and maintenance.
Furthermore, evidence is showing that miR-21 could be interacting with apoptosis-regulating proteins and important tumor suppressors, allowing for prolonged cell survival and unchecked growth and proliferation. $\mathrm{Li}$ et al. found that when miR-21 was suppressed in U373 MG glioblastoma cells, the cells were significantly resensitized to VM-26, a topoisomerase-II inhibitor. The group found that miR21 directly targets leucine rich repeat (in FLII) interacting protein 1 (LRRFIP1), a protein with downstream products in 
the tumor necrosis factor receptor family [83]. Yang et al. showed that prolonged exposure to cisplatin in SGC7901 cells, a gastric cancer cell line, significantly upregulated miR-21 expression and downregulated PTEN expression. Inhibition of miR-21 resensitized the cisplatin-resistant SGC7901 cells to cisplatin, a platinum-based chemodrug that triggers DNA crosslinking [7]. Based on these findings miR-21 is acting in a wide variety of roles across a variety of cancers. The ubiquitous nature and overexpression of miR-21 in cancers make it a valuable target of great clinical significance.

4.2. $m i R-125 b$. The oncomiR miR-125 is of great importance in breast cancer, as there has been a growing body of evidence suggesting that it plays a crucial role in initiation, metastasis, and recurrence. Current research is slightly split on the role of miR-125b with more research suggesting that miR-125b is important in conferring therapy resistant phenotypes in a variety of cancers rather than a therapy sensitive phenotype. Zhou et al. found that inhibition of miR$125 \mathrm{~b}$ resensitized cells to paclitaxel due to miR-125b directly targeting Bak1, a proapoptotic factor, in a suite of breast cancer cell lines [99]. Similarly, Liu et al. showed that miR$125 \mathrm{~b}$ was significantly upregulated in taxol-resistant breast cancer cell lines. Further research has elucidated that Snail upregulates miR-125b which directly targets Bak1, thereby reducing chemosensitivity to gemcitabine and taxol [100]. Likewise, Wang et al. showed a negative correlation between circulating miR-125b levels in breast cancer patients and treatment response and a positive correlation between miR$125 \mathrm{~b}$ levels and disease severity. By directly targeting the cell cycle regulator E2F3 miR-125b has been shown to increase resistance to 5-FU in a variety of breast cancer cell lines [101]. Outside of breast cancer lines, Iida et al. found that miR$125 \mathrm{~b}$ was upregulated in doxorubicin-resistant derivatives of the Ewing sarcoma lines, WE-68 and VH-64. Once again, miR-125b was targeting Bak1 and p53, thereby decreasing chemosensitivity to doxorubicin [102].

4.3. miRNAs Targeting Tumor Suppressors. As previously mentioned, PTEN and p53 are critical tumor suppressors that are often dysregulated in many cancers. Emerging research suggests that a wide variety of miRNAs target PTEN and p53 allowing for cancer cells to proliferate and grow at an alarming rate. Additionally, the suppression of PTEN and p53 helps to grant a chemoresistant phenotype across several cancers. Fu et al. showed that miR-93 was significantly upregulated in CDDP resistant variations of the ovarian cancer lines OVCAR3 and SKOV3 and in primary tumor samples. Further analysis revealed that miR-93 binds to the $3^{\prime}$ UTR of PTEN and regulates its expression [5]. The regulation of PTEN by miRNAs is also found in breast cancer. Liang et al. found that inhibition of miR-19 in vitro and in vivo decreased cell viability and tumor growth, respectively. Liang et al. found miR-19 to directly target the tumor suppressor, PTEN, in MCF-7 cells [6]. Likewise, Guo et al. showed that when $\mathrm{c}-\mathrm{Myc}$ is overexpressed there was a significant increase in cell viability, while inhibition of cMyc significantly reduced cell viability in U87 and U251 glioblastoma multiforme cell lines. The group showed that the upregulation of c-Myc, a prominent oncogene, upregulates miR-26a, which then directly targets PTEN [8]. Li et al. found that miR-92b was dramatically upregulated in both non-small cell lung cancer tissue samples and cell lines. miR$92 \mathrm{~b}$ expression was found to significantly resensitize cells to cisplatin by directly targeting PTEN [9]. Zhao et al. found that when they suppressed miR-221, a cisplatin-sensitive phenotype was restored to the osteosarcoma cell lines, SOSP9607 and MG63. miR-221 was shown to be directly targeting PTEN in the cell lines [10]. Liu et al. found that miR-375 desensitizes the cells to etoposide, a topoisomerase inhibitor, and to ionizing radiation by directly targeting p53 in MCF7, AGS, and A549 cell lines [11]. The expression of both of these well-known tumor suppressors is typically down in most cancers, but these findings help to elucidate a possible mechanism through which this downregulation occurs and offer clinical targets for slowing tumor progression. This ever expanding and critical overlap between oncomiRs and tumor suppressors may serve to illuminate the most effective targets for supplementing current cancer therapeutics.

\section{5. miRNAs as Cancer Therapy Sensitizers}

5.1. let-7 Interactions with Chemotherapy. Research has also uncovered several families of miRNAs that are significantly reduced in most cancers. A wealth of current research strongly suggests that the let-7 family can significantly sensitize cancer cells to therapy, reduce proliferation, reduce invasion, and reduce cell growth. Chen et al. found that the levels of let-7a in patients with acute myeloid leukemia (AML) correlated significantly with better prognosis, and upregulation of let-7a in vitro or in vivo significantly resensitized AML to cytarabine (also known as Ara-C) treatment. This group found that let-7a is regulated by CXCR4 in acute myeloid leukemia [67]. Lv et al. from the same group as Wang et al. found that lin28 regulation of let-7a also affected chemoresistance in SK-BR-3 cells. Downregulation of lin28 decreased resistance to paclitaxel and high levels of lin 28 correlated with metastasis and/or relapse [68]. Bhutia et al. showed that $\operatorname{lin} 28$ and SET regulated processing of let$7 \mathrm{a}$ in pancreatic cancer cell lines. Furthermore, they found that resistance to gemcitabine correlated with a buildup of unprocessed pre-let-7 along with an increase of RRM2, a potential target of let-7a that is involved in the reduction of ribonucleotides to deoxyribonucleotides [70]. Thus, $\operatorname{lin} 28$ may serve as an important therapeutic target, in addition to the use of let-7 mimics.

Guo et al. showed that let- $7 \mathrm{~b}$ reconstitution restored a cisplatin-sensitive phenotype in U251 cells. Additionally, cyclin D1 is a direct target of let-7b, with knockdown of cyclin D1 yielding a phenotype similar to let-7b reconstitution [71]. Sugimura et al. found that let- $7 \mathrm{c}$ regulates the interleukin6/STAT3 prosurvival pathway in esophageal cancer. When let-7c was highly expressed, the $\mathrm{IC}_{50}$ for cisplatin was significantly decreased and the overall survival times for patients were increased [72]. Along those lines, Zhao et al. showed that higher levels of let-7c in NSCLC correlated with longer survival times in patients, with carcinoma tissues in patients typically having significantly lower levels of let-7c 
than normal tissues. Let-7c was shown to be directly targeting integrin $\beta_{3}$ and MAP4K3. Restoration of let-7c expression inhibited proliferation, invasion, and migration in vitro [127]. Cai et al. found that cisplatin treatment downregulated let7e expression in ovarian cancer cell lines. The group found that enhancer of zeste homolog 2 (EZH2) and cyclin D1, both thought to play a role in drug resistance, are potentially regulated by let-7e. Reexpression of let-7e in vivo significantly slowed tumor progression and reduced EZH2 and cyclin D1 expression [73]. The let-7 family is proving to be critical across a wide variety of cancer types, with reexpression often having significant effects, making it an excellent target for future clinical use.

\section{2. miR-200 Family Interactions with Chemotherapies.} Another emerging metastasis suppressor and therapy sensitizer is the miR-200 family. The miR-200 family, while particularly known for its role in suppressing EMT, is proving to play an additional role in mediating cancer cell response to traditional therapeutic regimens. Much of the current research on the miR-200 family has focused particularly on miR-200a, -200b, and -200c, with far less research looking at miR-141 and miR-429. Soubani et al. showed that the curcumin analog, difluorinated curcumin (CDF), is able to upregulate miR-200a, $-200 \mathrm{~b}$, and $-200 \mathrm{c}$ in pancreatic cancer lines. Additionally, it was shown that the expression of CDF upregulated the critical tumor suppressor PTEN [128]. Furthering this, Ali et al. found that CDF-mediated upregulation of miR-200b and miR-200c along with CDF-mediated downregulation of miR-21 elevated PTEN levels and suppressed NF- $\kappa$ B DNA binding activity. The modulations of these microRNAs significantly resensitized pancreatic cancer cells to gemcitabine [80].

Kopp et al. found that reconstitution of miR-200c in breast cancer significantly sensitized cells to doxorubicin. Furthermore, miR-200c expression was found to be targeting Bmil and $\operatorname{TrkB}$, a potential oncogene and a survival factor, respectively [116]. Cochrane et al. showed that reexpression of miR-200c in ovarian cancer-where expression is typically reduced-significantly resensitized cells to paclitaxel [117]. On the other hand, Prislei et al. showed that miR-200c levels can have varying effects on ovarian cancer. The group showed that TUBB3, a potential target of miR-200c, has both a 200c binding site and a HuR binding site. Depending on the location of $\mathrm{HuR}$, patients with high miR-200c levels had either a better (nuclear HuR) or worse (cytoplasmic HuR) prognosis, with regard to survival time and progression free survival, due to differential interactions of miR-200c with TUBB3 [129]. Lastly, Hur et al. found that restoration of miR200c to miR-200c deficient colorectal cancer lines yielded a significant increase in cell proliferation. However, there was a marked decrease in cell invasion and migration, suggesting a critical role for miR-200c in suppressing an EMT phenotype. Through luciferase reporter assay the group found that miR200c targets ZEB1, protein C-ets-1 (ETS1), and vascular endothelial growth factor receptor 1 (FLT1) [130].

5.3. Various miRNA Interactions with Irradiation. While a vast amount of current research focuses on miRNAs in combination with chemotherapy, a small body of studies examines irradiation treatments in conjunction with miRNA treatment. The alteration of miRNAs involved in DNA damage repair due to radiation would allow for cancer cells to resist radiation treatment [131-133]. To this extent, Huang et al. focused on RAD51 and its paralog RAD51D, two proteins involved in homologous recombination mediated double strand break repair. The group found that miR-107, which directly targeted RAD51 and RAD51D, and miR-103 when upregulated in the human osteosarcoma cell line U20S sufficiently resensitized cells to irradiation and several chemotherapeutics [96].

Wang et al. showed that overexpression of lin28, a cancer stem cell marker, in SK-BR-3 breast cancer cells, downregulated let-7a. Restoration of let-7a expression significantly resensitized cells to radiation treatment [69]. Wang et al. found that $\mathrm{miR}-23 \mathrm{~b}$ expression was down in radiation resistant lines of pancreatic cancer cells. When reexpressed, cells were far more sensitive to radiation treatment both in vitro and in vivo. The group found that miR-23b targets ATG12, thereby regulating autophagy [88].

Zhang et al. showed that miR-29c is frequently downregulated in nasopharynx cancers. Restoration of typical miR29c levels significantly resensitized cells to irradiation and cisplatin in vitro and significantly reduced tumor growths in vivo. It was shown that miR-29c suppresses both Mcl-1 and Bcl-2 [89]. Yang et al. found that miR-145 is typically downregulated in glioblastoma multiforme patients. Reexpression of miR-145 created a temozolomide and irradiation sensitive phenotype in vitro and in vivo, with an impressively significant reduction in tumor growth. MiR-145 was found to directly target both Oct 4 and Sox 2 [108]. Liang et al. showed that miR-302 replacement therapy significantly resensitized breast cancer cells to irradiation in vivo and in vitro by directly targeting AKT1 and RAD52 [120].

A more comprehensive look at miRNA interactions with traditional therapies can be found in Table 2.

\section{6. miRNA Delivery Systems}

One of the issues to be confronted with miRNAs in treatment is the system of delivery. A variety of means from nanotechnology to lipids to viruses have been explored, each with its own advantages and setbacks.

6.1. Nanotechnology-Based miRNA Delivery Systems. Much of the current research on miRNA delivery is trending towards the use of nanotechnologies. Ando et al. found that the use of dicetyl phosphate-tetraethylenepentamine-based polycation liposomes was significantly more effective than $\mathrm{N}$-[1-(2,3-dioleoyloxy)propyl]-N,N,N-trimethylammonium methylsulfate-based liposomes (DOTAP) for delivering miR92a to human umbilical vein endothelial cells (HUVECs) and releasing it into the cytoplasm [134]. Biray et al. showed that the use of polyethylene glycol-polyethylenimine nanocomplexes was approximately $80 \%$ more effective than control reagents in delivering miR-150 into chronic myeloid leukemia cells [135]. Likewise, Yang et al. found that the use of cationic polyurethane-short branch polyethylenimine for 
TABLE 2: miRNAs in combination with traditional cancer therapies.

\begin{tabular}{|c|c|c|}
\hline $\operatorname{miR}$ & Cancer type (effect of expression on treatment) & Treatments investigated \\
\hline let-7a & $\begin{array}{l}\text { Leukemia [67] (sensitive), breast }[68,69] \text { (sensitive), pancreatic } \\
\text { [70] (sensitive) }\end{array}$ & $\begin{array}{l}\text { Ara-C, irradiation, paclitaxel, } \\
\text { gemcitabine }\end{array}$ \\
\hline let-7b & Glioblastoma [71] (sensitive) & Cisplatin \\
\hline let-7c & Esophageal [72] (sensitive) & Cisplatin \\
\hline let-7e & Ovarian [73] (sensitive) & Cisplatin \\
\hline miR-9 & Glioblastoma [74] (resistant) & Temozolomide \\
\hline miR-10b & Colon [75] (resistant) & Fluorouracil \\
\hline miR-15b & Tongue [76] (sensitive) & Gemcitabine \\
\hline $\operatorname{miR}-17-5 p$ & Pancreatic [77] (resistant) & Gemcitabine \\
\hline miR-19a & Breast [6] (resistant) & Taxol, mitoxantrone, etoposide \\
\hline miR-21 & $\begin{array}{l}\text { Gastric [7] (resistant), pancreatic [78-80] (resistant), } \\
\text { glioblastoma [81-84] (resistant), colorectal }[85,86] \text { (resistant), } \\
\text { adenocarcinoma [87] (resistant) }\end{array}$ & $\begin{array}{l}\text { Gemcitabine, fluorouracil, temozolomide, } \\
\text { irradiation, cisplatin }\end{array}$ \\
\hline miR-23b & Pancreatic [88] (sensitive) & Irradiation \\
\hline $\operatorname{miR}-29 c$ & Nasopharynx [89] (sensitive) & Cisplatin, irradiation \\
\hline miR-30c & Breast [90] (sensitive) & Paclitaxel, doxorubicin \\
\hline $\begin{array}{l}\text { miR-30d, miR-181a and } \\
\text { miR-199a-5p }\end{array}$ & Colorectal, prostate, and leukemia [91] (sensitive) & Trichostatin A \\
\hline miR-31 & Ovarian [92] (sensitive) & Paclitaxel \\
\hline $\operatorname{miR}-34 a$ & $\begin{array}{l}\text { Breast [93] (sensitive), prostate [94] (sensitive), gastric [95] } \\
\text { (miR-34c-5p, sensitive) }\end{array}$ & Adriamycin, camptothecin, paclitaxel \\
\hline miR-92b & Lung [9] (resistant) & Cisplatin \\
\hline miR-93 & Ovarian [5] (resistant) & Cisplatin \\
\hline miR-103 and miR-107 & Osteosarcoma, cervical, lung [96] (sensitive) & $\begin{array}{l}\text { AZD2281, cisplatin, etoposide, } \\
\text { camptothecin, irradiation }\end{array}$ \\
\hline miR-106a & Ovarian $[97,98]$ (sensitive or resistant) & Cisplatin, paclitaxel \\
\hline miR-125b & Breast [99-101] (resistant), Ewing sarcoma [102] (sensitive) & $\begin{array}{l}\text { Paclitaxel, fluorouracil, doxorubicin, } \\
\text { gemcitabine }\end{array}$ \\
\hline miR-128-2 & Lung [103] (resistant) & Cisplatin, doxorubicin, fluorouracil \\
\hline miR-130a & Liver [104] (resistant) & Cisplatin \\
\hline miR-140 & Osteosarcoma and colon [105] (resistant) & Fluorouracil \\
\hline miR-141 & Ovarian [106] (resistant) & Cisplatin \\
\hline miR-143 and miR-145 & Colon [107] (sensitive) & Fluorouracil, irinotecan, oxaliplatin \\
\hline miR-145 & Glioblastoma [108] (sensitive), cervical [109] (sensitive) & Irradiation, temozolomide, mitomycin \\
\hline miR-152 and miR-185 & Ovarian [110] (sensitive) & Cisplatin \\
\hline miR-181b & $\begin{array}{l}\text { Pancreatic }[111,112] \text { (sensitive or resistant), glioblastoma [113] } \\
\text { (sensitive) }\end{array}$ & Gemcitabine, temozolomide \\
\hline miR-182 & Ovarian [114] (resistant) & Paclitaxel, cisplatin \\
\hline miR-199a-5p & Liver [115] (sensitive) & Cisplatin \\
\hline miR-200b & Pancreatic [80] (sensitive), tongue [75] (sensitive) & Gemcitabine, cisplatin \\
\hline miR-200c & $\begin{array}{l}\text { Pancreatic [80] (sensitive), breast [116] (sensitive), ovarian [117] } \\
\text { (sensitive) }\end{array}$ & Gemcitabine, paclitaxel, doxorubicin \\
\hline $\operatorname{miR}-223$ & Liver [118] (sensitive) & Doxorubicin, paclitaxel \\
\hline $\operatorname{miR}-298$ & Breast [119] (sensitive) & Doxorubicin \\
\hline $\mathrm{miR}-302$ & Breast [120] (sensitive) & Irradiation \\
\hline $\operatorname{miR}-320$ & Prostate [121] (sensitive), pancreatic [122] (miR-320c, resistant) & $\begin{array}{l}\text { Cisplatin, carboplatin, paclitaxel, } \\
\text { gemcitabine }\end{array}$ \\
\hline
\end{tabular}


TABLE 2: Continued.

\begin{tabular}{lll}
\hline miR & Cancer type (effect of expression on treatment) & Treatments investigated \\
\hline miR-375 & Gastric [11] (resistant), cervical [123] (resistant) & Irradiation, etoposide, paclitaxel \\
miR-591 & Ovarian [97] (sensitive) & Paclitaxel \\
miR-650 & Lung [124] (resistant) & Docetaxel \\
miR-663 & Breast [125] (resistant) & Adriamycin, chlorophosphamide, \\
miR-708 & Ewing sarcoma [126] (sensitive) & docetaxel \\
& & Etoposide, doxorubicin \\
\hline
\end{tabular}

miR-145 significantly reduced glioblastoma multiforme tumor sizes in vivo. Impressively, the addition of irradiation and temozolomide nearly removed all traces of tumors [108]. Lastly, Cao et al. showed that protamine sulfate-nanodiamond hybrid nanoparticle delivery of miR-203 significantly reduced cell migration and proliferation in the esophageal cancer cell line, Ec-109 [136]. The emergence of nanotechnology as a delivery mechanism, particularly within the last year, is significant for clinical development of miRNA therapies.

6.2. Lipid-Based miRNA Delivery Systems. In the past, cationic lipid and polymer based delivery systems have suffered from cytotoxic side effects in vivo, mainly due to their cationic nature. Many of these systems contain common organic structures, creating biochemical consequences in the cell [137]. However, recent advances in the field have yielded promising results. Griveau et al. found that lipid nanocapsule-locked nucleic acid complexes targeting miR21 in glioblastoma cells significantly resensitized the cells to irradiation at 48 hours after transfection as compared to N-TER Nanoparticle siRNA Transfection System, a current transfection reagent [82]. Similarly, Shi et al. found that solid lipid nanoparticles were effective in delivering anti-miR-21 oligonucleotides to lung cancer cells in vitro. This group saw a significant decrease in migration and invasion along with a significant increase in apoptosis of these cancer cells [138]. Moreover, Trang et al. showed that a neutral lipid emulsion containing either miR-34a or let-7b significantly reduced lung tumor growth in vivo [139]. Piao et al. showed that lipidbased nanoparticles were effective in delivering pre-miR107 to neck and squamous cancer cells in vivo. Analysis of the tumors revealed a significant reduction in tumor growth and an increase in survival [140]. Current advances may make lipid-based delivery systems viable methods of delivery within the next few years.

6.3. Virus-Based miRNA Delivery Systems. Viral delivery systems, while far more efficient than other mechanisms, frequently elicit immunogenic responses, hindering their overall effectiveness. Because of this significant limitation, viral delivery systems have been primarily limited to in vitro work, with retroviruses playing an important role in RNAi research. Current research on the practicality of viral delivery systems for miRNAs is extremely limited and as such is only mentioned for the sake of acknowledgement.

\section{Challenges and Perspectives}

While miRNAs have a wealth of potential, the field has several challenges that it still needs to address. There are limitations for using circulating miRNAs as potential biomarkers for cancer earlier diagnosis. One of the limitations is the reported inconsistence of circulating miRNA alterations in a particular type of cancer. For example, the levels of a good number of (>30) miRNAs have been found to be significantly changed (increased or decreased) in gastric cancer patients' blood, serum, or plasma samples [141]. Nevertheless, the observed alterations of circulating miRNAs are mostly sporadic with little consensus among different studies. Few circulating miRNAs were found to be similarly and significantly altered in three or more than three studies.

As is usually a problem with most pharmaceutics, miRNAs in therapy would require an effective delivery system. Much of the current research for this is focusing on various nanotechnologies in hopes of reducing the toxicity seen in some current delivery mechanisms. The selected delivery systems must meet several criteria with no major issues of safety and efficient use. Much of the current research on the safety of RNA interference in vivo revolves around shRNAs, but there may still be some applicability in the results. Grimm et al. found that overexpression of over 30 different shRNAs in vivo caused liver toxicity and ultimately death in several mice. The group found that miRNAs and shRNAs were competing for cellular processing equipment leading to a buildup of premature miRNAs and shRNAs [142].

Many research groups reintroduce miRNAs through the use of pre-miRNAs. This influx of unprocessed miRNAs could flood the miRNA processing system and lead to toxic, and potentially lethal, side effects. However, Liu et al. showed that while lentiviral delivery of miR-30 to melanomas had comparable effects on cancer progression in vivo similar to shRNAs, miR-30 had little incidence of inflammation [143]. So it is possible that miRNAs could attenuate some of the side effects of shRNAs, but this is a gap in knowledge that will need filling as the field moves closer to clinical applications. However, this hurdle of investigating safety and miRNA delivery in vivo is just beginning to be met and is the next major challenge to the field on its way to full clinical application.

The field of miRNA use in cancer therapy is most likely heading in a direction that is more oriented towards in vivo investigation and translational research. However, presently, 
there are some cancers that are far more represented in the literature than others. The current literature is more geared towards cancers such as glioblastomas, breast, ovarian, nonsmall cell lung, and pancreatic than it is towards cancers like kidney and leukemia. It is the hope of the authors that these gaps in research will soon be filled in, bringing all cancers to a comparable level of understanding. However, the future of the field is a bright one and clinical applications will hopefully come to fruition within the next decade.

\section{Conflict of Interests}

The authors declare that there is no conflict of interests regarding the publication of this paper.

\section{References}

[1] R. C. Lee, R. L. Feinbaum, and V. Ambros, "The C. elegans heterochronic gene lin-4 encodes small RNAs with antisense complementarity to lin-14," Cell, vol. 75, no. 5, pp. 843-854, 1993.

[2] K. Chen and N. Rajewsky, "The evolution of gene regulation by transcription factors and microRNAs," Nature Reviews Genetics, vol. 8, no. 2, pp. 93-103, 2007.

[3] R. C. Friedman, K. K. Farh, C. B. Burge, and D. P. Bartel, "Most mammalian mRNAs are conserved targets of microRNAs," Genome Research, vol. 19, no. 1, pp. 92-105, 2009.

[4] P. B. Kwak, S. Iwasaki, and Y. Tomari, "The microRNA pathway and cancer," Cancer Science, vol. 101, no. 11, pp. 2309-2315, 2010.

[5] X. Fu, J. Tian, L. Zhang, Y. Chen, and Q. Hao, "Involvement of microRNA-93, a new regulator of PTEN/Akt signaling pathway, in regulation of chemotherapeutic drug cisplatin chemosensitivity in ovarian cancer cells," FEBS Letters, vol. 586, no. 9, pp. 1279-1286, 2012.

[6] Z. Liang, Y. Li, K. Huang, N. Wagar, and H. Shim, "Regulation of miR-19 to breast cancer chemoresistance through targeting PTEN," Pharmaceutical Research, vol. 28, no. 12, pp. 3091-3100, 2011.

[7] S.-M. Yang, C. Huang, X.-F. Li, M.-Z. Yu, Y. He, and J. Li, "miR21 confers cisplatin resistance in gastric cancer cells by regulating PTEN," Toxicology, vol. 306, pp. 162-168, 2013.

[8] P. Guo, Q. Nie, J. Lan, J. Ge, Y. Qiu, and Q. Mao, "C-Myc negatively controls the tumor suppressor PTEN by upregulating miR-26a in glioblastoma multiforme cells," Biochemical and Biophysical Research Communications, vol. 441, pp. 186-190, 2013.

[9] Y. Li, L. Li, Y. Guan, X. Liu, and Q. Meng, "MiR-92b regulates the cell growth, cisplatin chemosensitivity of A549 non small cell lung cancer cell line and target PTEN," Biochemical and Biophysical Research, vol. 440, pp. 604-610, 2013.

[10] G. Zhao, C. Cai, T. Yang et al., "MicroRNA-221 induces cell survival and cisplatin resistance through PI3K/Akt pathway in human osteosarcoma," PLoS ONE, vol. 8, no. 1, Article ID e53906, 2013.

[11] Y. Liu, R. Xing, X. Zhang et al., "MiR-375 targets the p53 gene to regulate cellular response to ionizing radiation and etoposide in gastric cancer cells," DNA Repair, vol. 12, no. 9, pp. 741-750, 2013.

[12] M. Korpal, E. S. Lee, G. Hu, and Y. Kang, "The miR-200 family inhibits epithelial-mesenchymal transition and cancer cell migration by direct targeting of E-cadherin transcriptional repressors ZEB1 and ZEB2," Journal of Biological Chemistry, vol. 283, no. 22, pp. 14910-14914, 2008.
[13] S. Park, A. B. Gaur, E. Lengyel, and M. E. Peter, "The miR-200 family determines the epithelial phenotype of cancer cells by targeting the E-cadherin repressors ZEB1 and ZEB2," Genes and Development, vol. 22, no. 7, pp. 894-907, 2008.

[14] H. Schwarzenbach, N. Nishida, G. A. Calin, and K. Pantel, "Clinical relevance of circulating cell-free microRNAs in cancer," Nature Reviews Clinical Oncology, vol. 11, pp. 145-156, 2014.

[15] J. Wang, K.-Y. Zhang, S.-M. Liu, and S. Sen, "Tumor-associated circulating microRNAs as biomarkers of cancer," Molecules, vol. 19, no. 2, pp. 1912-1938, 2014.

[16] F. L. Yong, C. W. Law, and C. W. Wang, "Potentiality of a triple microRNA classifier: miR-193a-3p, miR-23a and miR-338-5p for early detection of colorectal cancer," BMC Cancer, vol. 13, article 280, 2013.

[17] S. Wach, E. Nolte, J. Szczyrba et al., "MicroRNA profiles of prostate carcinoma detected by multiplatform microRNA screening," International Journal of Cancer, vol. 130, no. 3, pp. 611-621, 2012.

[18] S.-K. Leivonen, K. K. Sahlberg, R. Mäkelä et al., "Highthroughput screens identify microRNAs essential for HER2 positive breast cancer cell growth," Molecular Oncology, vol. 8, no. 1, pp. 93-104, 2014.

[19] M. A. Lemmon and J. Schlessinger, "Cell signaling by receptor tyrosine kinases," Cell, vol. 141, no. 7, pp. 1117-1134, 2010.

[20] P. Fasanaro, Y. D’Alessandra, V. Di Stefano et al., "MicroRNA210 modulates endothelial cell response to hypoxia and inhibits the receptor tyrosine kinase ligand ephrin-A3," Journal of Biological Chemistry, vol. 283, no. 23, pp. 15878-15883, 2008.

[21] C. Oneyama, J. Ikeda, D. Okuzaki et al., "MicroRNA-mediated downregulation of mTOR/FGFR3 controls tumor growth induced by Src-related oncogenic pathways," Oncogene, vol. 30, no. 32, pp. 3489-3501, 2011.

[22] M. Acunzo, G. Romano, D. Palmieri et al., "Cross-talk between MET and EGFR in non-small cell lung cancer involves miR-27a and Sprouty2," Proceedings of the National Academy of Sciences of the United States of America, vol. 110, no. 21, pp. 8573-8578, 2013.

[23] M. MacKiewicz, K. Huppi, J. J. Pitt, T. H. Dorsey, S. Ambs, and N. J. Caplen, "Identification of the receptor tyrosine kinase $A X L$ in breast cancer as a target for the human miR-34a microRNA," Breast Cancer Research and Treatment, vol. 130, no. 2, pp. 663679, 2011.

[24] C. Feng, V. Neumeister, W. Ma et al., "Lin28 regulates HER2 and promotes malignancy through multiple mechanisms," Cell Cycle, vol. 11, no. 13, pp. 2486-2494, 2012.

[25] S. A. M. Rao, A. Arimappamagan, P. Pandey et al., "miR-219-5p inhibits receptor tyrosine kinase pathway by targeting EGFR in glioblastoma," PLoS ONE, vol. 8, no. 5, Article ID e63164, 2013.

[26] J.-E. Kwon, B.-Y. Kim, S.-Y. Kwak, I.-H. Bae, and Y.-H. Han, "Ionizing radiation-inducible microRNA miR-193a-3p induces apoptosis by directly targeting Mcl-1," Apoptosis, vol. 18, no. 7, pp. 896-909, 2013.

[27] W. Zhang, J.-X. Qian, H.-L. Yi et al., “The microRNA-29 plays a central role in osteosarcoma pathogenesis and progression," Molecular Biology, vol. 46, no. 4, pp. 557-562, 2012.

[28] F. Ji, H. Zhang, Y. Wang et al., "MicroRNA-133a, downregulated in osteosarcoma, suppresses proliferation and promotes apoptosis by targeting Bcl-xL and Mcl-1," Bone, vol. 56, no. 1, pp. 220226, 2013.

[29] R. Guo, Y. Wang, W.-Y. Shi, B. Liu, S.-Q. Hou, and L. Liu, "MicroRNA miR-491-5p targeting both TP53 and BclXL induces cell apoptosis in SW1990 pancreatic cancer cells 
through mitochondria mediated pathway," Molecules, vol. 17, no. 12, pp. 14733-14747, 2012.

[30] Q. Ji, X. Hao, M. Zhang et al., "MicroRNA miR-34 inhibits human pancreatic cancer tumor-initiating cells," PLOS ONE, vol. 4, no. 8, Article ID e6816, 2009.

[31] H. Zhang, Y. Li, Q. Huang et al., "MiR-148a promotes apoptosis by targeting Bcl-2 in colorectal cancer," Cell Death \& Differentiation, vol. 18, no. 11, pp. 1702-1710, 2011.

[32] A. Cimmino, G. A. Calin, M. Fabbri et al., "miR-15 and miR-16 induce apoptosis by targeting BCL2," Proceedings of the National Academy of Sciences of the United States of America, vol. 102, no. 39, pp. 13944-13949, 2005.

[33] C. J. Lin, H. Y. Gong, H. C. Tseng, W. L. Wang, and J. L. Wu, "miR-122 targets an anti-apoptotic gene, $B c l-w$, in human hepatocellular carcinoma cell lines," Biochemical and Biophysical Research Communications, vol. 375, no. 3, pp. 315-320, 2008.

[34] J. Downward, "Targeting RAS signalling pathways in cancer therapy," Nature Reviews Cancer, vol. 3, no. 1, pp. 11-22, 2003.

[35] A. L. Kasinski and F. J. Slack, "MiRNA-34 prevents cancer initiation and progression in a therapeutically resistant K-ras and p53-induced mouse model of lung adenocarcinoma," Cancer Research, vol. 72, no. 21, pp. 5576-5587, 2012.

[36] D. Sun, F. Yu, Y. Ma et al., "MicroRNA-31 activates the RAS pathway and functions as an oncogenic MicroRNA in human colorectal cancer by repressing RAS p21 GTPase activating protein 1 (RASA1)," The Journal of Biological Chemistry, vol. 288, no. 13, pp. 9508-9518, 2013.

[37] K.-H. Shin, S. D. Bae, H. S. Hong, R. H. Kim, M. K. Kang, and N. Park, "miR-181a shows tumor suppressive effect against oral squamous cell carcinoma cells by downregulating K-ras," Biochemical and Biophysical Research Communications, vol. 404, no. 4, pp. 896-902, 2011.

[38] J.-Y. Jang, Y.-S. Lee, Y.-K. Jeon, K. Lee, J.-J. Jang, and C. W. Kim, "ANT2 suppression by shRNA restores miR-636 expression, thereby downregulating Ras and inhibiting tumorigenesis of hepatocellular carcinoma," Experimental and Molecular Medicine, vol. 45, no. 1, article e3, 2013.

[39] R. Wang, Z.-X. Wang, J.-S. Yang, X. Pan, W. De, and L.-B. Chen, "MicroRNA-451 functions as a tumor suppressor in human non-small cell lung cancer by targeting ras-related protein 14 (RAB14)," Oncogene, vol. 30, no. 23, pp. 2644-2658, 2011.

[40] P. Liu, M. Qi, C. Ma et al., "Let7a inhibits the growth of endometrial carcinoma cells by targeting Aurora-B," FEBS Letters, vol. 587, no. 16, pp. 2523-2529, 2013.

[41] Z. Shi, J. Zhang, X. Qian, L. Han, K. Zhang et al., "AC1MMYR2, an inhibitor of dicer-mediated biogenesis of oncomir miR21, reverses epithelial-mesenchymal transition and suppresses tumor growth and progression," Cancer Res, vol. 73, pp. 55195531, 2013.

[42] T. Tao, Y. Wang, H. Luo et al., "Involvement of FOS-mediated miR-181b/miR-21 signalling in the progression of malignant gliomas," European Journal of Cancer, vol. 49, no. 14, pp. 30553063, 2013.

[43] H. Tang, Y. Kong, J. Guo et al., "Diallyl disulfide suppresses proliferation and induces apoptosis in human gastric cancer through Wnt-1 signaling pathway by up-regulation of miR-200b and miR-22," Cancer Letters, vol. 340, pp. 72-81, 2013.

[44] X. Fu, Z. Meng, W. Liang, Y. Tian, and X. Wang, "miR-26a enhances miRNA biogenesis by targeting Lin28B and Zcchc11 to suppress tumor growth and metastasis," Oncogene, 2013.
[45] Y. Lin, H. Chen, Z. Hu et al., "MiR-26a inhibits proliferation and motility in bladder cancer by targeting HMGA1," FEBS Letters, vol. 587, no. 15, pp. 2467-2473, 2013.

[46] N. Banerjee, S. Talcott, S. Safe, and S. U. Mertens-Talcott, "Cytotoxicity of pomegranate polyphenolics in breast cancer cells in vitro and vivo: potential role of miRNA-27a and miRNA-155 in cell survival and inflammation," Breast Cancer Research and Treatment, vol. 136, no. 1, pp. 21-34, 2012.

[47] J. Ye, X. Wu, D. Wu et al., "miRNA-27b targets vascular endothelial growth factor $\mathrm{C}$ to inhibit tumor progression and angiogenesis in colorectal cancer," PLoS ONE, vol. 8, no. 4, Article ID e60687, 2013.

[48] M. Garofalo, Y. J. Jeon, G. J. Nuovo et al., "MiR-34a/c-dependent PDGFR- $\alpha / \beta$ downregulation inhibits tumorigenesis and enhances TRAIL-induced apoptosis in lung cancer," PLoS ONE, vol. 8, no. 6, Article ID e67581, 2013.

[49] F. Liu, J. Gong, W. Huang et al., "MicroRNA-106b-5p boosts glioma tumorigensis by targeting multiple tumor suppressor genes," Oncogene, 2013.

[50] G. Zhao, J.-G. Zhang, Y. Shi et al., "MiR-130b is a prognostic marker and inhibits cell proliferation and invasion in pancreatic cancer through targeting STAT3," PLoS ONE, vol. 8, no. 9, Article ID e73803, 2013.

[51] S. Qiu, D. Huang, D. Yin et al., "Suppression of tumorigenicity by MicroRNA-138 through inhibition of EZH2-CDK4/6-pRbE2F1 signal loop in glioblastoma multiforme," Biochimica et Biophysica Acta-Molecular Basis of Disease, vol. 1832, no. 10, pp. 1697-1707, 2013.

[52] H. Wu, Z. Xiao, K. Wang, W. Liu, and Q. Hao, "MiR-145 is downregulated in human ovarian cancer and modulates cell growth and invasion by targeting p70S6K1 and MUC1," Biochemical and Biophysical Research Communications, vol. 441, no. 4, pp. 693-700, 2013.

[53] J.-P. Zhang, C. Zeng, L. Xu, J. Gong, and J.-H. Fang, "MicroRNA-148a suppresses the epithelial-mesenchymal transition and metastasis of hepatoma cells by targeting Met/Snail signaling," Oncogene, 2013.

[54] N. Zhang, X. Wei, and L. Xu, "MiR-150 promotes the proliferation of lung cancer cells by targeting P53," FEBS Letters, vol. 587, no. 15, pp. 2346-2351, 2013.

[55] W. Kong, L. He, E. J. Richards et al., "Upregulation of miRNA155 promotes tumour angiogenesis by targeting VHL and is associated with poor prognosis and triple-negative breast cancer," Oncogene, vol. 33, pp. 679-689, 2014.

[56] C. Zhang, J. Zhao, and H. Deng, "17beta-estradiol up-regulates miR-155 expression and reduces TP53INP1 expression in MCF7 breast cancer cells," Molecular and Cellular Biochemistry, vol. 379, no. 1-2, pp. 201-211, 2013.

[57] Y. Wang, Y. Yu, A. Tsuyada et al., "Transforming growth factor$\mathrm{B}$ regulates the sphere-initiating stem cell-like feature in breast cancer through miRNA-181 and ATM," Oncogene, vol. 30, no. 12, pp. 1470-1480, 2011.

[58] X. Li, Y. T. Chen, S. Josson et al., “MicroRNA-185 and 342 inhibit tumorigenicity and induce apoptosis through blockade of the SREBP metabolic pathway in prostate cancer cells," PLoS ONE, vol. 8, no. 8, Article ID e70987, 2013.

[59] J.-S. Kim, S.-Y. Park, S. A. Lee et al., "MicroRNA-205 suppresses the oral carcinoma oncogenic activity via down-regulation of Axin-2 in KB human oral cancer cell," Molecular and Cellular Biochemistry, vol. 387, no. 1-2, pp. 71-79, 2014. 
[60] S. Sarkar, H. Dubaybo, S. Ali, P. Goncalves, and S. L. Kollepara, "Down-regulation of miR-221 inhibits proliferation of pancreatic cancer cells through up-regulation of PTEN, p27 ${ }^{\text {kip } 1}$, p57 kip2 , and PUMA," American Journal of Cancer Research, vol. 3, pp. 465-477, 2013.

[61] R. Nassirpour, P. P. Mehta, S. M. Baxi, and M.-J. Yin, “miR-221 promotes tumorigenesis in human triple negative breast cancer cells," PLoS ONE, vol. 8, no. 4, Article ID e62170, 2013.

[62] F. Ma, J. Zhang, L. Zhong et al., "Upregulated microRNA-301a in breast cancer promotes tumor metastasis by targeting PTEN and activating Wnt / $\beta$-catenin signaling," Gene, vol. 535 , no. 2 , pp. 191-197, 2014.

[63] A. Martin, A. Jones, P. J. Bryar et al., "MicroRNAs-449a and -449 b exhibit tumor suppressive effects in retinoblastoma," Biochemical and Biophysical Research, vol. 440, pp. 599-603, 2013.

[64] S.-Y. Kwak, J.-S. Yang, B.-Y. Kim, I. H. Bae, and Y.-H. Han, "Ionizing radiation-inducible miR-494 promotes glioma cell invasion through EGFR stabilization by targeting p190B RhoGAP," Biochimica et Biophysica Acta, vol. 1843, no. 3, pp. 508-516, 2014.

[65] L. Creevey, J. Ryan, H. Harvey et al., "MicroRNA-497 increases apoptosis in MYCN amplified neuroblastoma cells by targeting the key cell cycle regulator WEE1," Molecular Cancer, vol. 12, no. 1, article 23, 2013.

[66] T. Song, X. Zhang, L. Zhang et al., "MiR-708 promotes the development of bladder carcinoma via direct repression of Caspase-2," Journal of Cancer Research and Clinical Oncology, vol. 139, no. 7, pp. 1189-1198, 2013.

[67] Y. Chen, R. Jacamo, M. Konopleva, R. Garzon, C. Croce, and M. Andreeff, "CXCR4 downregulation of let-7a drives chemoresistance in acute myeloid leukemia," Journal of Clinical Investigation, vol. 123, no. 6, pp. 2395-2407, 2013.

[68] K. Lv, L. Liu, L. Wang et al., "Lin28 mediates paclitaxel resistance by modulating $\mathrm{p} 21, \mathrm{Rb}$ and Let-7a miRNA in breast cancer cells," PLoS ONE, vol. 7, no. 7, Article ID e40008, 2012.

[69] L. Wang, C. Yuan, K. Lv et al., "Lin28 mediates radiation resistance of breast cancer cells via regulation of caspase, H2A.X and let-7 signaling," PLoS ONE, vol. 8, no. 6, Article ID e67373, 2013.

[70] Y. D. Bhutia, S. W. Hung, M. Krentz et al., "Differential Processing of let-7a Precursors Influences RRM2 Expression and Chemosensitivity in Pancreatic Cancer: Role of LIN-28 and SET Oncoprotein," PLoS ONE, vol. 8, no. 1, Article ID e53436, 2013.

[71] Y. Guo, K. Yan, J. Fang, Q. Qu, M. Zhou, and F. Chen, "Let-7b expression determines response to chemotherapy through the regulation of Cyclin D1 in Glioblastoma," Journal of Experimental and Clinical Cancer Research, vol. 32, no. 1, article 41, 2013.

[72] K. Sugimura, H. Miyata, K. Tanaka et al., "Let-7 expression is a significant determinant of response to chemotherapy through the regulation of IL-6/STAT3 pathway in esophageal squamous cell carcinoma," Clinical Cancer Research, vol. 18, no. 18, pp. 5144-5153, 2012.

[73] J. Cai, C. Yang, Q. Yang, H. Ding, and J. Jia, "Deregulation of let-7e in epithelial ovarian cancer promotes the development of resistance to cisplatin," Oncogenesis, vol. 2, article e75, 2013.

[74] J. L. Munoz, S. A. Bliss, S. J. Greco, S. H. Ramkissoon, and K. L. Ligon, "Delivery of functional anti-miR-9 by mesenchymal stem cell-derived exosomes to glioblastoma multiforme cells conferred chemosensitivity," Molecular Therapy Nucleic Acids, vol. 2, article e126, 2013.

[75] N. Nishida, S. Yamashita, K. Mimori et al., "MicroRNA-10b is a prognostic indicator in colorectal cancer and confers resistance to the chemotherapeutic agent 5-fluorouracil in colorectal cancer cells," Annals of Surgical Oncology, vol. 19, no. 9, pp. 3065-3071, 2012.

[76] L. Sun, Y. Yao, B. Liu et al., "MiR-200b and miR-15b regulate chemotherapy-induced epithelial-mesenchymal transition in human tongue cancer cells by targeting BMI1," Oncogene, vol. 31, no. 4, pp. 432-445, 2012.

[77] H. J. Yan, W. S. Liu, W. H. Sun et al., "MiR-17-5p inhibitor enhances chemosensitivity to gemcitabine via upregulating bim expression in pancreatic cancer cells," Digestive Diseases and Sciences, vol. 57, no. 12, pp. 3160-3167, 2012.

[78] W. H. Paik, H. R. Kim, J. K. Park, B. J. Song, S. H. Lee, and J. Hwang, "Chemosensitivity induced by down-regulation of MicroRNA-21 in gemcitabine-resistant pancreatic cancer cells by indole-3-carbinol," Anticancer Research, vol. 33, no. 4, pp. 1473-1482, 2013.

[79] J. H. Hwang, J. Voortman, E. Giovannetti et al., "Identification of microRNA-21 as a biomarker for chemoresistance and clinical outcome following adjuvant therapy in resectable pancreatic cancer," PLoS ONE, vol. 5, no. 5, Article ID e10630, 2010.

[80] S. Ali, A. Ahmad, S. Banerjee et al., "Gemcitabine sensitivity can be induced in pancreatic cancer cells through modulation of miR-200 and miR-21 expression by curcumin or its analogue CDF," Cancer Research, vol. 70, no. 9, pp. 3606-3617, 2010.

[81] S. T. S. Wong, X.-Q. Zhang, J. T.-F. Zhuang, H.-L. Chan, C.-H. Li, and G. K. K. Leung, "MicroRNA-21 inhibition enhances in vitro chemosensitivity of temozolomide-resistant glioblastoma cells," Anticancer Research, vol. 32, no. 7, pp. 2835-2842, 2012.

[82] A. Griveau, J. Bejaud, S. Anthiya, S. Avril, D. Autret, and E. Garcion, "Silencing of miR-21 by locked nucleic acid-lipid nanocapsule complexes sensitize human glioblastoma cells to radiation-induced cell death," International Journal of Pharmaceutics, vol. 454, pp. 765-774, 2013.

[83] Y. Li, W. Li, Y. Yang et al., "MicroRNA-21 targets LRRFIP1 and contributes to VM-26 resistance in glioblastoma multiforme," Brain Research, vol. 1286, pp. 13-18, 2009.

[84] H.-S. Gwak, T. H. Kim, G. H. Jo et al., "Silencing of microRNA21 confers radio-sensitivity through inhibition of the PI3K/AKT pathway and enhancing autophagy in malignant glioma cell lines," PLoS ONE, vol. 7, no. 10, Article ID e47449, 2012.

[85] J. Deng, W. Lei, J.-C. Fu, L. Zhang, J.-H. Li, and J.-P. Xiong, "Targeting miR-21 enhances the sensitivity of human colon cancer HT-29 cells to chemoradiotherapy in vitro," Biochemical and Biophysical Research Communications, vol. 443, no. 3, pp. 789-795, 2014.

[86] N. Valeri, P. Gasparini, C. Braconi et al., "MicroRNA-21 induces resistance to 5 -fluorouracil by down-regulating human DNA MutS homolog 2 (hMSH2)," Proceedings of the National Academy of Sciences of the United States of America, vol. 107, no. 49, pp. 21098-21103, 2010.

[87] M. O. Elhassan, J. Christie, and M. S. Duxbury, "Homo sapiens systemic RNA interference-defective-1 transmembrane family member 1 (SIDT1) protein mediates contact-dependent small RNA transfer and microRNA-21-driven chemoresistance," Journal of Biological Chemistry, vol. 287, no. 8, pp. 5267-5277, 2012.

[88] P. Wang, J. Zhang, L. Zhang et al., "MicroRNA 23b regulates autophagy associated with radioresistance of pancreatic cancer cells," Gastroenterology, vol. 145, pp. 1133-1143, 2013.

[89] J. Zhang, D. Qian, F. Wang et al., "MicroRNA-29c enhances the sensitivities of human nasopharyngeal carcinoma to cisplatinbased chemotherapy and radiotherapy," Cancer Letters, vol. 329, no. 1, pp. 91-98, 2013. 
[90] J. Bockhorn, R. Dalton, C. Nwachukwu et al., "MicroRNA30c inhibits human breast tumour chemotherapy resistance by regulating TWF1 and IL-11," Nature Communications, vol. 4, article 1393, 2013.

[91] S. F. Su, Y. W. Chang, C. Andreu-Vieyra et al., "miR-30d, miR181a and miR-199a-5p cooperatively suppress the endoplasmic reticulum chaperone and signaling regulator GRP78 in cancer," Oncogene, pp. 4694-4701, 2012.

[92] T. Mitamura, H. Watari, L. Wang et al., "Downregulation of miRNA-31 induces taxane resistance in ovarian cancer cells through increase of receptor tyrosine kinase MET,' Oncogenesis, vol. 2, article e40, 2013.

[93] X. Li, M. Ji, S. Zhong et al., "MicroRNA-34a modulates chemosensitivity of breast cancer cells to adriamycin by targeting Notch1," Archives of Medical Research, vol. 43, no. 7, pp. 514-521, 2012.

[94] Y. Fujita, K. Kojima, N. Hamada et al., "Effects of miR-34a on cell growth and chemoresistance in prostate cancer PC3 cells," Biochemical and Biophysical Research Communications, vol. 377, no. 1, pp. 114-119, 2008.

[95] H. Wu, M. Huang, M. Lu et al., "Regulation of microtubuleassociated protein tau (MAPT) by miR-34c-5p determines the chemosensitivity of gastric cancer to paclitaxel," Cancer Chemotherapy and Pharmacology, vol. 71, no. 5, pp. 1159-1171, 2013.

[96] J.-W. Huang, Y. Wang, K. K. Dhillon, P. Calses, and E. Villegas, "Systematic screen identifies miRNAs that target RAD51 and RAD51D to enhance chemosensitivity," Molecular Cancer Research, vol. 11, no. 12, pp. 1564-1573, 2013.

[97] Y. Rao, H. Shi, M. Ji, and C. Chen, "MiR-106a targets Mcl-1 to suppress cisplatin resistance of ovarian cancer A2780 cells," Journal of Huazhong University of Science and Technology, vol. 33, no. 4, pp. 567-572, 2013.

[98] J. H. Huh, T. H. Kim, K. Kim et al., "Dysregulation of miR-106a and miR-591 confers paclitaxel resistance to ovarian cancer," British Journal of Cancer, vol. 109, no. 2, pp. 452-461, 2013.

[99] M. Zhou, Z. Liu, Y. Zhao et al., "MicroRNA-125b confers the resistance of breast cancer cells to paclitaxel through suppression of pro-apoptotic Bcl-2 antagonist killer 1 (Bak1) expression," Journal of Biological Chemistry, vol. 285, no. 28, pp. 2149621507, 2010.

[100] Z. Liu, H. Liu, S. Desai et al., "MiR-125b functions as a key mediator for snail-induced stem cell propagation and chemoresistance," Journal of Biological Chemistry, vol. 288, no. 6, pp. 4334-4345, 2013.

[101] H. Wang, G. Tan, L. Dong et al., "Circulating mir-125b as a marker predicting chemoresistance in breast cancer," PLoS ONE, vol. 7, no. 4, Article ID e34210, 2012.

[102] K. Iida, J. Fukushi, Y. Matsumoto et al., "MiR-125b develops chemoresistance in Ewing sarcoma/primitive neuroectodermal tumor," Cancer Cell International, vol. 13, no. 1, article 21, 2013.

[103] S. Donzelli, G. Fontemaggi, F. Fazi et al., "MicroRNA-128-2 targets the transcriptional repressor E2F5 enhancing mutant p53 gain of function," Cell Death and Differentiation, vol. 19, no. 6, pp. 1038-1048, 2012.

[104] N. Xu, C. Shen, Y. Luo et al., "Upregulated miR-130a increases drug resistance by regulating RUNX3 and Wnt signaling in cisplatin-treated HCC cell," Biochemical and Biophysical Research Communications, vol. 425, no. 2, pp. 468-472, 2012.

[105] B. Song, Y. Wang, Y. Xi et al., "Mechanism of chemoresistance mediated by miR-140 in human osteosarcoma and colon cancer cells," Oncogene, vol. 28, no. 46, pp. 4065-4074, 2009.
[106] M. T. M. van Jaarsveld, J. Helleman, A. W. M. Boersma et al., "miR-141 regulates KEAP1 and modulates cisplatin sensitivity in ovarian cancer cells," Oncogene, pp. 4284-4293, 2012.

[107] A. Pagliuca, C. Valvo, E. Fabrizi et al., "Analysis of the combined action of miR-143 and miR-145 on oncogenic pathways in colorectal cancer cells reveals a coordinate program of gene repression," Oncogene, vol. 32, pp. 4806-4813, 2012.

[108] Y. P. Yang, Y. Chien, G. Y. Chiou et al., "Inhibition of cancer stem cell-like properties and reduced chemoradioresistance of glioblastoma using microRNA145 with cationic polyurethaneshort branch PEI," Biomaterials, vol. 33, no. 5, pp. 1462-1476, 2012.

[109] M. Shi, L. Du, D. Liu et al., "Glucocorticoid regulation of a novel HPV-E6-p53- MiR-145 pathway modulates invasion and therapy resistance of cervical cancer cells," Journal of Pathology, vol. 228, no. 2, pp. 148-157, 2012.

[110] Y. Xiang, N. Ma, D. Wang, Y. Zhang, and J. Zhou, "MiR-152 and miR-185 co-contribute to ovarian cancer cells cisplatin sensitivity by targeting DNMT1 directly: a novel epigenetic therapy independent of decitabine," Oncogene, vol. 33, no. 3, pp. 378-386, 2014.

[111] B. Cai, Y. An, N. Lv et al., "miRNA-181b increases the sensitivity of pancreatic ductal adenocarcinoma cells to gemcitabine in vitro and in nude mice by targeting BCL-2," Oncology Reports, vol. 29, no. 5, pp. 1769-1776, 2013.

[112] D. Takiuchi, H. Eguchi, H. Nagano et al., "Involvement of microRNA-181b in the gemcitabine resistance of pancreatic cancer cells," Pancreatology, vol. 13, pp. 517-523, 2013.

[113] J. Wang, K. Sai, F.-R. Chen, and Z.-P. Chen, "miR-181b modulates glioma cell sensitivity to temozolomide by targeting MEK1," Cancer Chemotherapy and Pharmacology, vol. 72, no. 1, pp. 147-158, 2013.

[114] Y.-Q. Wang, R.-D. Guo, W.-M. Sheng, and L.-R. Yin, "MicroRNA-182 promotes cell growth, invasion, and chemoresistance by targeting programmed cell death 4 (PDCD4) in human ovarian carcinomas," Journal of Cellular Biochemistry, vol. 114, no. 7, pp. 1464-1473, 2013.

[115] N. Xu, J. Zhang, C. Shen et al., "Cisplatin-induced downregulation of miR-199a-5p increases drug resistance by activating autophagy in HCC cell," Biochemical and Biophysical Research Communications, vol. 423, no. 4, pp. 826-831, 2012.

[116] F. Kopp, P. S. Oak, E. Wagner, and A. Roidl, “miR-200c sensitizes breast cancer cells to doxorubicin treatment by decreasing TrkB and Bmil expression," PLoS ONE, vol. 7, no. 11, Article ID e50469, 2012.

[117] D. R. Cochrane, E. N. Howe, N. S. Spoelstra, and J. K. Richer, "Loss of miR-200c: a marker of aggressiveness and chemoresistance in female reproductive cancers," Journal of Oncology, vol. 2010, Article ID 821717, 12 pages, 2010.

[118] T. Yang, Z.-M. Zheng, X.-N. Li et al., "MiR-223 modulates multidrug resistance via downregulation of $\mathrm{ABCB} 1$ in hepatocellular carcinoma cells," Experimental Biology and Medicine, vol. 238, no. 9, pp. 1024-1032, 2013.

[119] L. Bao, S. Hazari, S. Mehra, D. Kaushal, K. Moroz, and S. Dash, "Increased expression of P-glycoprotein and doxorubicin chemoresistance of metastatic breast cancer is regulated by miR-298," American Journal of Pathology, vol. 180, no. 6, pp. 2490-2503, 2012.

[120] Z. Liang, J. Ahn, D. Guo, J. R. Votaw, and H. Shim, "MicroRNA302 replacement therapy sensitizes breast cancer cells to ionizing radiation," Pharmaceutical Research, vol. 30, no. 4, pp. 10081016, 2013. 
[121] I.-S. Hsieh, K. Chang, Y. Tsai et al., "MicroRNA-320 suppresses the stem cell-like characteristics of prostate cancer cells by downregulating the Wnt/beta-catenin signaling pathway," Carcinogenesis, vol. 34, no. 3, pp. 530-538, 2013.

[122] Y. Iwagami, H. Eguchi, H. Nagano et al., "MiR-320c regulates gemcitabine-resistance in pancreatic cancer via SMARCCl," British Journal of Cancer, vol. 109, no. 2, pp. 502-511, 2013.

[123] Y. Shen, P. Wang, Y. Li et al., "MiR-375 is upregulated in acquired paclitaxel resistance in cervical cancer," British Journal of Cancer, vol. 109, no. 1, pp. 92-99, 2013.

[124] J. Huang, S. Cui, Y. Chen et al., "MicroRNA-650 was a prognostic factor in human lung adenocarcinoma and confers the docetaxel chemoresistance of lung adenocarcinoma cells via regulating Bcl-2/Bax expression," PLoS ONE, vol. 8, no. 8, Article ID e72615, 2013.

[125] H. Hu, S. Li, X. Cui et al., "The overexpression of hypomethylated miR-663 induces chemotherapy resistance in human breast cancer cells by targeting heparin sulfate proteoglycan 2 (HSPG2)," The Journal of Biological Chemistry, vol. 288, no. 16, pp. 10973-10985, 2013.

[126] T. P. Robin, A. Smith, E. McKinsey, L. Reaves, P. Jedlicka, and H. L. Ford, "EWS/FLI1 regulates EYA3 in Ewing sarcoma via modulation of miRNA-708, resulting in increased cell survival and chemoresistance," Molecular Cancer Research, vol. 10, no. 8, pp. 1098-1108, 2012.

[127] B. Zhao, H. Han, J. Chen et al., "MicroRNA let-7c inhibits migration and invasion of human non-small cell lung cancer by targeting ITGB3 and MAP4K3," Cancer Letters, vol. 342, pp. 43-51, 2014.

[128] O. Soubani, A. S. Ali, F. Logna, S. Ali, P. A. Philip, and F. H. Sarkar, "Re-expression of $m i R-200$ by novel approaches regulates the expression of PTEN and MT1-MMP in pancreatic cancer," Carcinogenesis, vol. 33, no. 8, pp. 1563-1571, 2012.

[129] S. Prislei, E. Martinelli, M. Mariani et al., "MiR-200c and HuR in ovarian cancer," BMC Cancer, vol. 13, article 72, 2013.

[130] K. Hur, Y. Toiyama, M. Takahashi et al., "MicroRNA-200c modulates epithelial-tomesenchymal transition (EMT) in human colorectal cancer metastasis," Gut, vol. 62, no. 9, pp. 1315-1326, 2013.

[131] Z. Guo, B. Zhou, W. Liu et al., "MiR-23a regulates DNA damage repair and apoptosis in UVB-irradiated HaCaT cells," Journal of Dermatological Science, vol. 69, no. 1, pp. 68-76, 2013.

[132] G. Tan, J. Niu, Y. Shi, H. Ouyang, and Z. Wu, "NF- $\kappa$ B-dependent MicroRNA-125b up-regulation promotes cell survival by targeting p38 $\alpha$ upon ultraviolet radiation," Journal of Biological Chemistry, vol. 287, no. 39, pp. 33036-33047, 2012.

[133] A. C. Mueller, D. Sun, and A. Dutta, “The miR-99 family regulates the DNA damage response through its target SNF2H," Oncogene, vol. 32, no. 9, pp. 1164-1172, 2013.

[134] H. Ando, A. Okamoto, M. Yokota et al., "Polycation liposomes as a vector for potential intracellular delivery of microRNA," The Journal of Gene Medicine, vol. 15, pp. 375-383, 2013.

[135] A. Biray, I. Özcan, T. Balci, Ö. Özer, and C. Gündüz, “Design of polyethylene glycol- polyethylenimine nanocomplexes as nonviral carriers: miR-150 delivery to chronic myeloid leukemia cells," Cell Biology International, vol. 37, pp. 1205-1214, 2013.

[136] M. Cao, X. Deng, S. Su, F. Zhang, and X. Xiao, "Protamine sulfate-nanodiamond hybrid nanoparticles as a vector for MiR203 restoration in esophageal carcinoma cells," Nanoscale, vol. 5, pp. 12120-12125, 2013.
[137] H. Lv, S. Zhang, B. Wang, S. Cui, and J. Yan, "Toxicity of cationic lipids and cationic polymers in gene delivery," Journal of Controlled Release, vol. 114, no. 1, pp. 100-109, 2006.

[138] S. J. Shi, Z. R. Zhong, J. Liu, Z. R. Zhang, X. Sun, and T. Gong, "Solid lipid nanoparticles loaded with anti-microRNA oligonucleotides (AMOs) for suppression of microRNA-21 functions in human lung cancer cells," Pharmaceutical Research, vol. 29, no. 1, pp. 97-109, 2012.

[139] P. Trang, J. F. Wiggins, C. L. Daige et al., "Systemic delivery of tumor suppressor microRNA mimics using a neutral lipid emulsion inhibits lung tumors in mice," Molecular Therapy, vol. 19, no. 6, pp. 1116-1122, 2011.

[140] L. Piao, M. Zhang, J. Datta et al., "Lipid-based nanoparticle delivery of pre-miR-107 inhibits the tumorigenicity of head and neck squamous cell carcinoma," Molecular Therapy, vol. 20, no. 6, pp. 1261-1269, 2012.

[141] X. Zhu, M. Lv, H. Wang, and W. Guan, "Identification of circulating microRNAs as novel potential biomarkers for gastric cancer detection: a systematic review and meta-analysis," Digestive Diseases and Sciences, vol. 59, no. 5, pp. 911-919, 2014.

[142] D. Grimm, K. L. Streetz, C. L. Jopling et al., "Fatality in mice due to oversaturation of cellular microRNA/short hairpin RNA pathways," Nature, vol. 441, no. 7092, pp. 537-541, 2006.

[143] X.-Y. Liu, Q.-S. Tang, H.-C. Chen, X.-L. Jiang, and H. Fang, "Lentiviral miR30-based RNA interference against heparanase suppresses melanoma metastasis with lower liver and lung toxicity," International Journal of Biological Sciences, vol. 9, no. 6, pp. 564-577, 2013. 

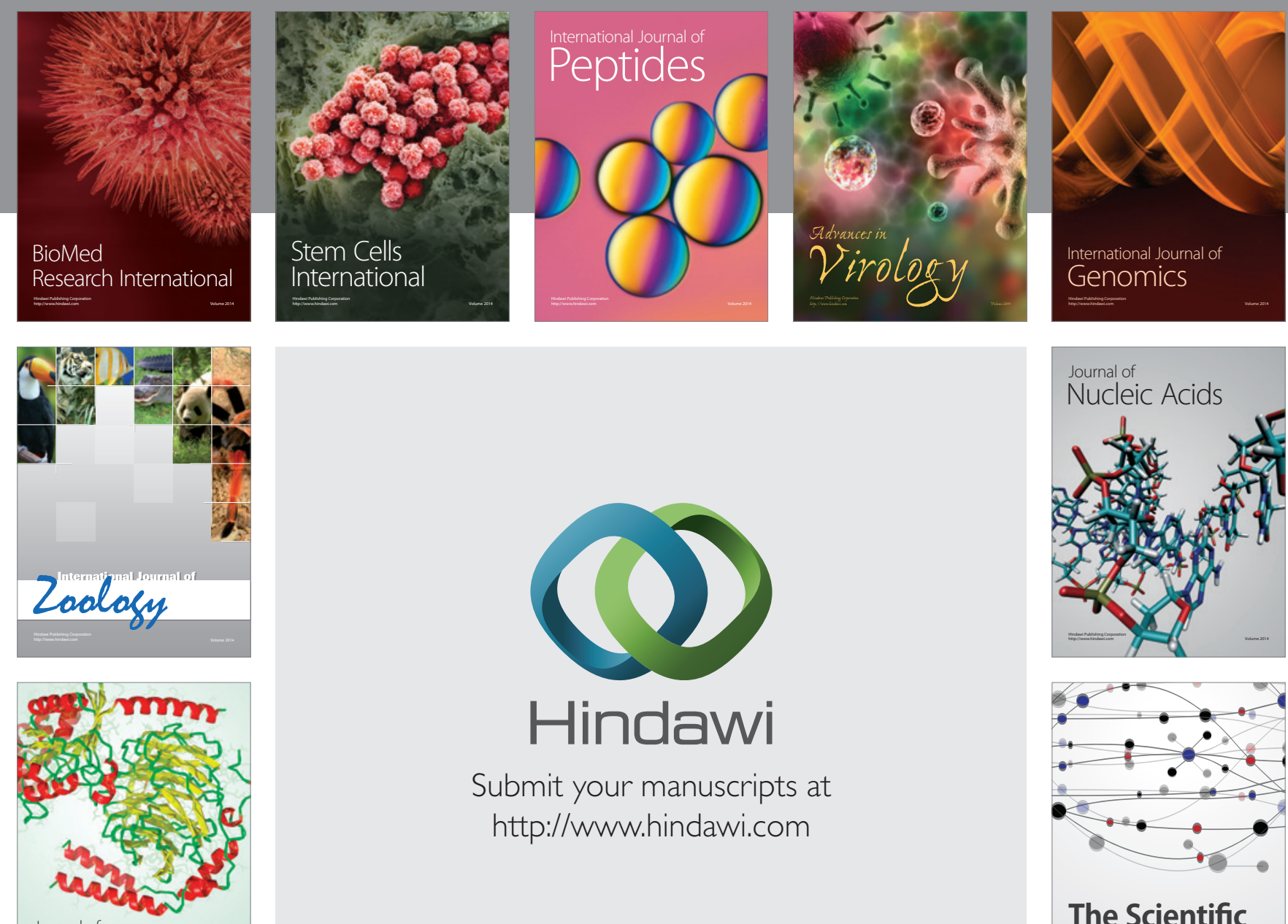

Submit your manuscripts at

http://www.hindawi.com

Journal of
Signal Transduction
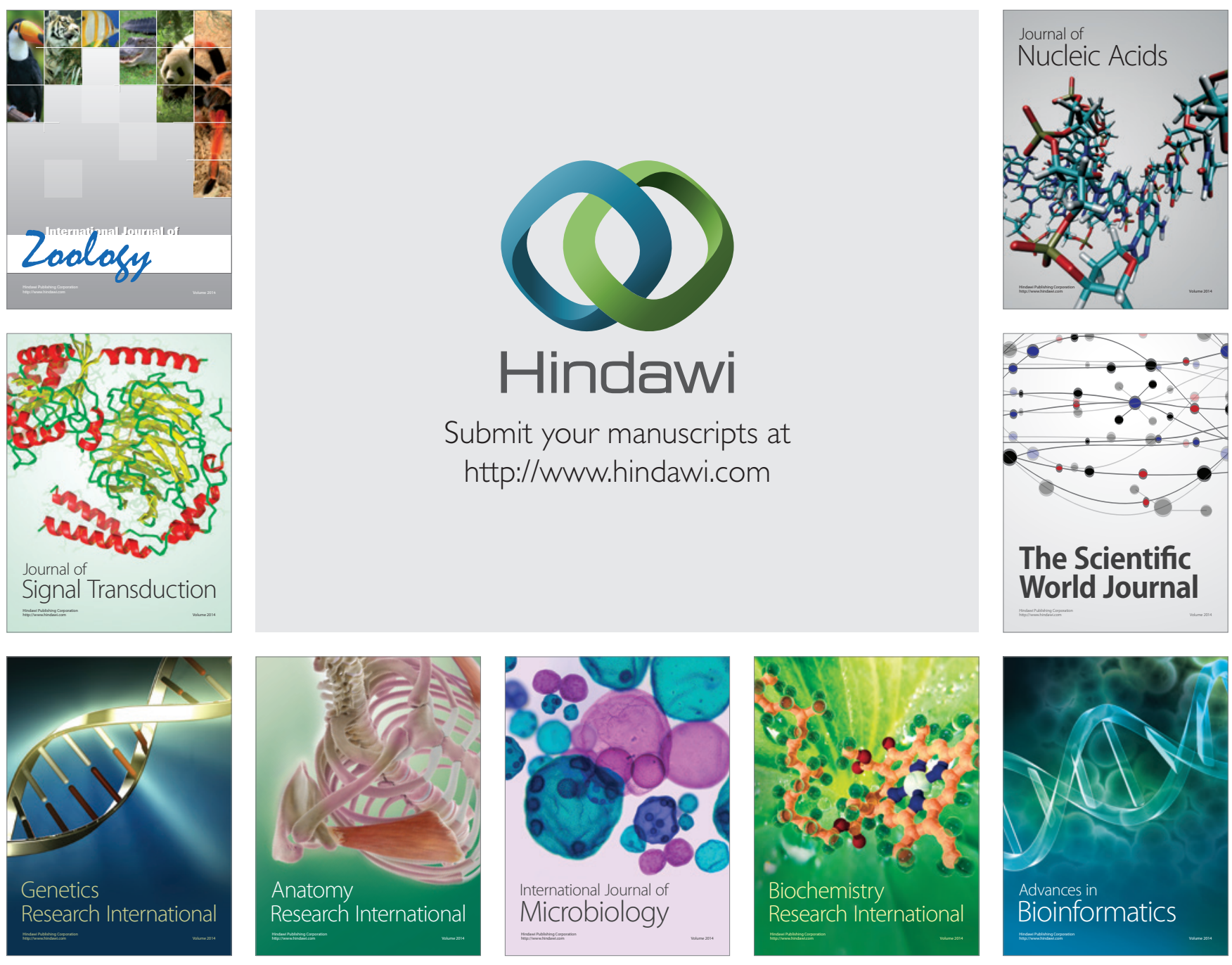

The Scientific World Journal
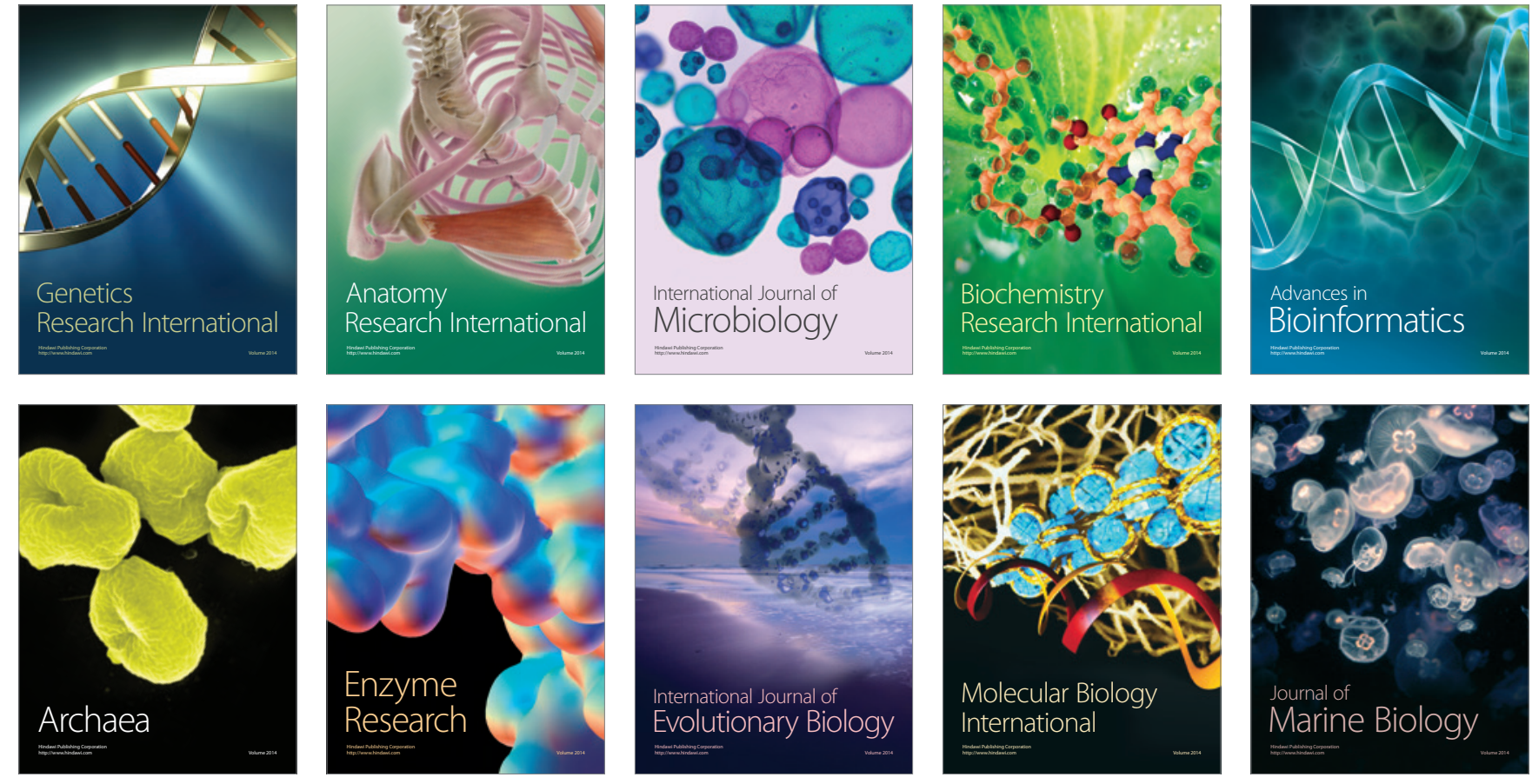